\title{
Depth-of-cure of Bulk-fill Composites Cured in Tooth or Opaque Substrate
}

\author{
${ }^{1}$ Brent W Church, ${ }^{2}$ Daranee Tantbirojn, ${ }^{3}$ Thuydung Do, ${ }^{4}$ Martha H Wells, ${ }^{5}$ Antheunis Versluis
}

\begin{abstract}
Purpose: To determine the effect of substrate on the depth-ofcure determination when using hardness profiles in a coveredslot technique and to introduce a new covered-slot method that uses tooth substrates.
\end{abstract}

Materials and methods: Three bulk-fill composites and one conventional composite were tested: Tetric EvoCeram Bulk Fill, Venus Bulk Fill, Filtek Bulk Fill Flowable, Filtek Supreme Ultra. The composites were light-cured in rectangular slots $(2 \mathrm{~mm}$ deep, $2 \mathrm{~mm}$ wide) made in a plaster mold or an extracted tooth. The slots were covered with an orange glass plate during curing, leaving one end exposed for light-curing. After curing, the glass plate was removed and the sample was stored in the dark for 24 hours before Vickers hardness was measured as a function of depth at $0.5-\mathrm{mm}$ intervals. Results were analyzed using twoway analysis of variance (ANOVA) and pairwise comparisons (significance level 0.05).

Results: The hardness of composites cured in covered-slot molds decreased with increasing depth $(p<0.001)$. Bulk-filled composites cured in plaster molds had a slightly lower depthof-cure than those cured in natural tooth substrates. Differences between the tooth and plaster substrates were significant at all depths in the "packable" bulk-fill composite (Tetric EvoCeram Bulk Fill), and were significant at $\geq 2.5$ and $\geq 3.5 \mathrm{~mm}$ in the flowable bulk-fill composites (Filtek Bulk Fill Flowable and Venus Bulk Fill) respectively.

Conclusion: Using natural tooth substrates in the covered-slot method increased the depth-of-cure of bulk-filled composites in comparison to opaque plaster molds.

Keywords: Bulk-fill, Composite, Depth-of-cure, Hardness, Tooth.

How to cite this article: Church BW, Tantbirojn D, Do T, Wells $\mathrm{MH}$, Versluis A. Depth-of-cure of Bulk-fill Composites Cured in Tooth or Opaque Substrate. Int J Experiment Dent Sci 2017;6(2):68-73.

\footnotetext{
${ }^{1,3}$ Private Practitioner, ${ }^{2}$ Professor, ${ }^{4}$ Associate Professor and Director, ${ }^{5}$ Professor and Director

${ }^{1}$ Department of Pediatric Dentistry, Prairie Village, Kansas, USA

${ }^{2}$ Department of Restorative Dentistry, University of Tennessee Health Science Center, Memphis, Tennessee, USA

${ }^{3}$ Department of Pediatric Dentistry, Arlington, Texas, USA

${ }^{4}$ Department of Pediatric Dentistry, University of Tennessee Health Science Center, Memphis, Tennessee, USA

${ }^{5}$ Department of Bioscience Research, University of Tennessee Health Science Center, Memphis, Tennessee, USA

Corresponding Author: Antheunis Versluis, Professor and Director, Department of Bioscience Research, University of Tennessee Health Science Center, Memphis, Tennessee, USA Phone: +19014486372 e-mail: antheun@uthsc.edu
}

Source of support: Supported by the University of Tennessee Health Science Center College of Dentistry Alumni Endowment Fund and the Tennessee Dental Association Foundation.

\section{Conflict of interest: None}

\section{INTRODUCTION}

Light-curing composite resins are one of the most widely used restorative dental materials. The placement of composite restorations is technique-sensitive and requires adequate light curing to ensure a thorough cure. ${ }^{1-3}$ Function and longevity of the restoration will be compromised if the composite is not sufficiently cured. ${ }^{4}$ Therefore, when restoring cavities with light-activated resin composites, it is recommended to cure the resin composite in increments no thicker than $2 \mathrm{~mm}$ to ensure an adequate cure. ${ }^{1-3}$ In order to overcome the $2 \mathrm{~mm}$ incremental composite placement limitation and thus decrease chair time, several manufacturers have introduced "bulk-fill" composites. These composites claim to cure adequately up to $4 \mathrm{~mm}$ deep, and hence, restorations can be filled in one increment ("bulk") when the cavity depth is less than $4 \mathrm{~mm} .{ }^{5-7}$ Research studies have shown mixed results: Some studies confirmed the manufacturers' claims while other studies found inadequate curing when cured in 4-mm bulk. ${ }^{8-15}$ Since adequate polymerization of the composite is critical to the success of the restoration, evaluation of the depth-ofcure of composites remains a vital topic in dental research.

The inconsistency in the literature regarding the depth-of-cure of bulk-filled composites can be a result of specific products or can be caused by methodology used for the measurements. Low-viscosity bulk-fill composites cure deeper than high-viscosity materials. ${ }^{3,15-17}$ The same composites showed different depth-of-cure when measured with different methods. A scraping test [International Organization for Standardization (ISO) 4049] ${ }^{18}$ overestimated the depth-of-cure compared with hardness tests, because partially cured material is usually rigid enough to be considered "cured". 3,8,12,19 A note in the 1992 ISO publication alludes to this observation by suggesting that the obtained depth-of-cure is about twice the optimal conversion of monomer or polymer. ${ }^{18}$ Hardness values represent load-bearing ability and have been correlated with the degree of conversion for resin materials. ${ }^{20,21}$ Hardness can be determined as the top/ bottom hardness ratio at prescribed depths $3,10-12,14,15,19$ or 
as hardness profiles through the depth. ${ }^{3,8,10,13,15,17,22}$ Both hardness methods reflect the relative extent of conversion of the deeper part of a restoration in relation to the top surface.

Substrate opacity and sample preparation techniques can also affect the depth-of-cure results. Composite samples can be made in a mold with a covered slot, which provides a unidirectional cure and a surface suitable for measuring hardness profiles. ${ }^{3,8,10,15,22-24}$ A wide range of mold substrates have been used in the aforementioned studies, including plaster, acrylic, Teflon, and stainless steel. The opacity of these substrates usually does not resemble tooth structures. Tooth enamel allows light to transmit to a degree that it can improve curing. ${ }^{25,26}$ On the contrary, in dentin, light attenuation can decrease depth-of-cure. ${ }^{27}$ To account for these clinical conditions, depth-of-cure is sometimes determined in restored teeth by cross-sectioning them. ${ }^{13,26}$ However, such cross-sectioned restorations must be embedded and polished to obtain surfaces that are smooth enough for accurate hardness measurements; those procedures could affect the surface hardness values.

The purpose of this study was to introduce an alternative method in which the mold is made in a tooth and to compare the depth-of-cure of bulk-filled composites in this tooth covered-slot method with a plaster covered-slot method. The null hypothesis was that depth-of-cure for samples cured in a tooth coveredslot method would not be different from those cured in a plaster covered-slot method.

\section{MATERIALS AND METHODS}

The depth-of-cure of three bulk-fill composites and one conventional composite was determined at 24 hours using
Vickers hardness profiles $(n=7)$. Material information is listed in Table 1.

\section{Plaster Covered-slot Method}

Plaster molds were made from dental stone (Whip Mix Microstone Model Stone Golden ISO type III, Whip Mix, Louisville, KY, USA) with rectangular slots (2 mm wide, $2 \mathrm{~mm}$ deep, $6 \mathrm{~mm}$ long). Composite was pressed into the slots and placed against an orange glass plate secured with a clamp (Figs 1A and B). The orange glass plate (Bullseye Glass Company, Portland, OR, USA) blocked blue light from reaching the slot surface, and thus ensured unidirectional light-curing. The end of the slot that was exposed to the curing-light was covered with a thin glass cover slip $(0.15 \mathrm{~mm})$ to create a smooth surface for the hardness measurement at the light-exposed surface ("0 $\mathrm{mm}$ "). The composite was light cured for 20 seconds while holding the light guide of a quartz-tungsten halogen unit (XL 3000, 3M ESPE, St. Paul, MN, USA) against the thin glass cover slip. The curing-light had an output of $450 \mathrm{~mW} / \mathrm{cm}^{2}$ measured with a curing radiometer (Model 100, Demetron Research Corp, Danbury, CT, USA). After light-curing, the glass covers were taken off and any uncured composite at the far end of the slot was removed. The samples were stored in a dark container for 24 hours. Microhardness was measured using a hardness tester (QV-1000 Micro Hardness Tester, Qualitest USA LC, Fort Lauderdale, FL, USA) with a Vickers indenter at $50 \mathrm{gm}$ load for 15 seconds dwell-time. Indentations were made at the $0 \mathrm{~mm}$ end and at $0.5 \mathrm{~mm}$ increments along the length of the composite in the slot (Fig. 1C).

Table 1: Material information

\begin{tabular}{|c|c|c|c|}
\hline Composite & Manufacturer & Lot & Composition \\
\hline Tetric EvoCeram Bulk Fill & $\begin{array}{l}\text { Ivoclar Vivodent, } \\
\text { Schaan, } \\
\text { Liechtenstein }\end{array}$ & $\begin{array}{l}\text { P87656 Shade: } \\
\text { IVW }\end{array}$ & $\begin{array}{l}\text { Resin: Dimethacrylates (Bis-GMA, Bis-EMA, UDMA) } \\
\text { Fillers: } 17 \% \text { prepolymers, Ba-Al-F (particle size } 0.4-0.7 \mu \mathrm{m} \text { ), } \\
\text { YbF }_{3} \text { (mean particle size } 200 \mathrm{~nm} \text { ) } \\
\text { Filler loading: } 61 \% \text { by volume }\end{array}$ \\
\hline Venus Bulk Fill & $\begin{array}{l}\text { Heraeus Kulzer } \\
\text { GmbH, Hanau, } \\
\text { Germany }\end{array}$ & $\begin{array}{l}10102 \text { Shade: } \\
\text { Universal }\end{array}$ & $\begin{array}{l}\text { Resin: UDMA, EBADMA } \\
\text { Fillers: Inorganic fillers, such as Ba-Al-F silicate glass, } \mathrm{YbF}_{3} \text {, and } \\
\mathrm{SiO}_{2} \text {. Filler particles size } 0.02-5 \mu \mathrm{m} \\
\text { Filler loading: } 65 \% \text { by weight } / 38 \% \text { by volume }\end{array}$ \\
\hline Filtek Bulk Fill Flowable & 3M ESPE, St & N510547 Shade: & Resin: Bis-GMA, UDMA, Bis-EMA(6), Procrylat resins \\
\hline Restorative & Paul, MN, USA & Universal & $\begin{array}{l}\text { Fillers: Zirconia/silica (particle size } 0.01-3.5 \mu \mathrm{m} \text { ), } \mathrm{YbF}_{3} \text { (particle } \\
\text { size } 0.02-5 \mu \mathrm{m} \text { ) } \\
\text { Filler loading: } \sim 64.5 \% \text { by weight } / 42.5 \% \text { by volume }\end{array}$ \\
\hline $\begin{array}{l}\text { Filtek Supreme Ultra } \\
\text { Universal Restorative }\end{array}$ & $\begin{array}{l}\text { 3M ESPE, St. } \\
\text { Paul, MN, USA }\end{array}$ & $\begin{array}{l}\text { N393610 Shade: } \\
\text { A2 }\end{array}$ & $\begin{array}{l}\text { Resin: Bis-GMA, Bis-EMA, UDMA, TEGDMA } \\
\text { Fillers: Nonagglomerated/nonaggregated } 20 \mathrm{~nm} \text { nanosilica } \\
\text { fillers and loosely bound agglomerates of } 5-20 \mathrm{~nm} \text { zirconia/silica } \\
\text { nanoclusters with particle sizes ranging between } 0.6 \text { and } 1.4 \mu \mathrm{m} \\
\text { Filler loading: } 78.5 \% \text { by weight }\end{array}$ \\
\hline
\end{tabular}

Bis-GMA: Bisphenol A diglycidyl ether dimethacrylate; Bis-EMA: Ethoxylated bisphenol A diglycidyl ether dimethacrylate; UDMA: Urethane dimethacrylate; EBADMA: Ethoxylated bisphenol A dimethacrylate; TEGDMA: Triethylene glycol dimethacrylate 

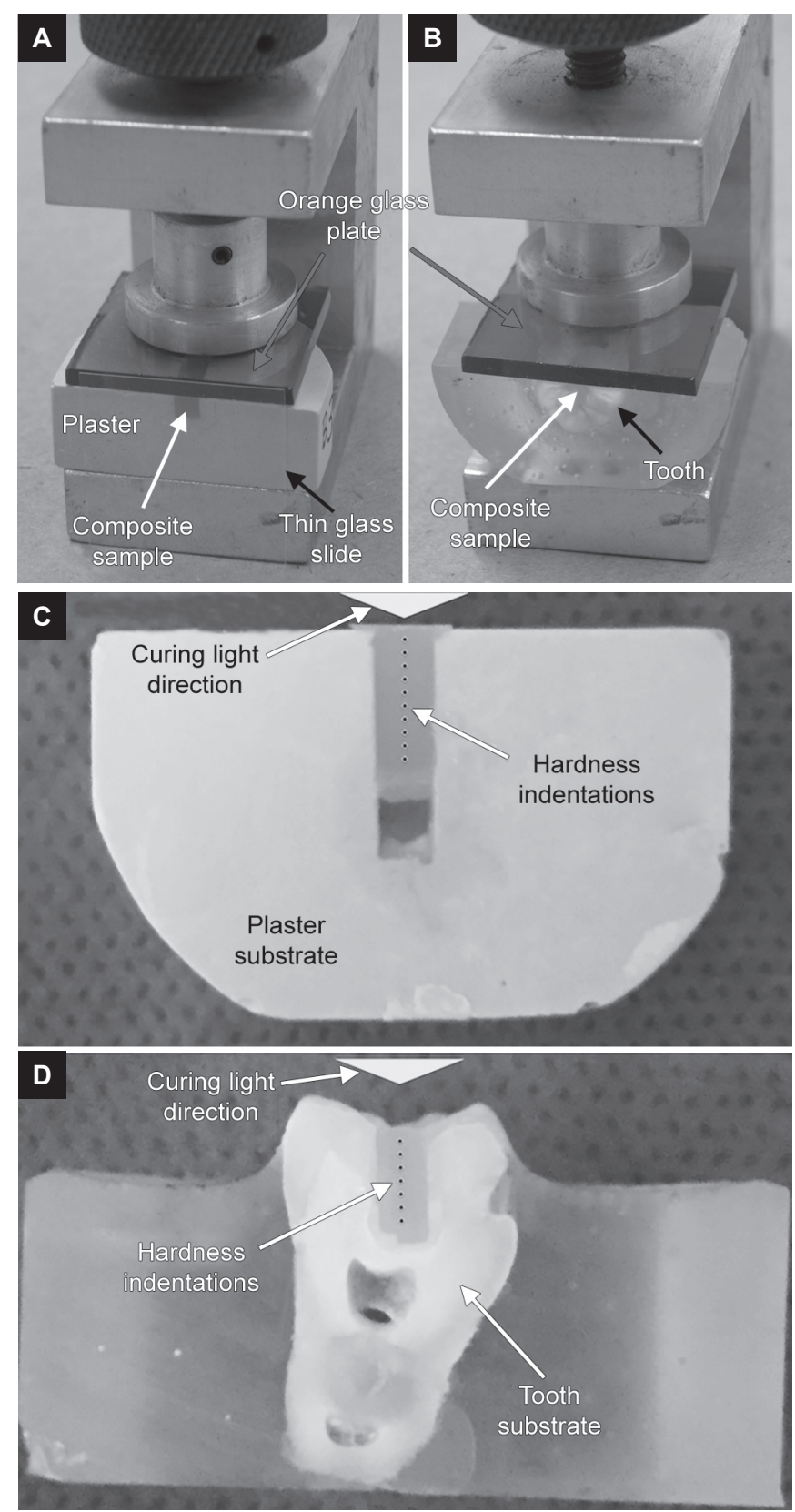

Figs 1A to D: (A) Composite filled slot was covered with an orange glass plate held in place with a clamp. Exposing only one end of the slot to the curing light ensured unidirectional light-curing of the composite; (B) Composite cured in slot made in tooth and covered with orange glass plate; (C) Positions of hardness indentations on composite sample cured in the plaster slot; and (D) Positions of hardness indentations of composite sample cured in the tooth slot

\section{Tooth Covered-slot Method}

Extracted teeth (Institutional Review Board approval 13-02486-XM) were embedded in clear acrylic resin (SamplKwick Acrylic, Buehler, Lake Bluff, Illinois, USA) and sectioned buccolingually into two halves. The sectioned teeth were prepared with rectangular slots $(2 \mathrm{~mm}$ wide, $2 \mathrm{~mm}$ deep, $4 \mathrm{~mm}$ long), to simulate a deep cavity (Fig. 1D). Composite was pressed into the slot and placed against the orange glass plate similar to the plaster method (Fig. 1B). The top (occlusal) surface was not covered with glass slip because that would require sectioning of the cusps. Hence, hardness measurements at the light-exposed surface (" $0 \mathrm{~mm}^{\prime}$ ) were not obtainable in the tooth coveredslot method. The composite was light cured from the occlusal direction with the light-guide pressed against the cusps, approximately $2 \mathrm{~mm}$ above the composite surface, using the aforementioned curing-light unit for 20 seconds. After light-curing, the orange glass cover was taken off and any uncured composite at the far end of the slot was removed. The samples were stored in a dark container for 24 hours. Vickers hardness was measured using the same parameters as the plaster covered-slot method. Indentations were made down the length of the slot along the long axis of the tooth at the center of the composite restoration (Fig. 1D) at $0.5 \mathrm{~mm}$ increments.

\section{Statistical Analysis}

Results were analyzed using two-way ANOVA and pairwise comparisons $(\alpha=0.05)$ to determine if there were statistically significant differences in Vickers hardness between the two covered-slot methods and among the depths within the same composite.

\section{RESULTS}

Vickers hardness numbers of composite samples in plaster slot or tooth slot at different depths are shown in Table 2 and the hardness profile plots in Graph 1. Hardness significantly decreased through the depths in all tested composites $(p<0.001$, Table 3$)$. The differences between the two covered-slot methods were significant in bulk-fill composites ( $\mathrm{p}<0.001)$, but not significant (NS) in the conventional composite $(\mathrm{p}=0.15)$. The Tetric EvoCeram Bulk Fill had significantly lower hardness, i.e., less depth-of-cure, in the plaster slot than the natural tooth substrate for most depths, whereas Venus Bulk Fill and Filtek Bulk Fill Flowable had significantly lower hardness in the plaster slot at $2.5 \mathrm{~mm}$ depth and beyond (Graph 1). As such, the interactions between depths and methods (Table 3) were only significant in Venus Bulk Fill ( $p=0.04)$ and Filtek Bulk Fill Flowable ( $\mathrm{p}=0.01)$, and NS in Tetric EvoCeram Bulk Fill composite ( $p=0.84$ ) and the conventional composite $(\mathrm{p}=0.998)$.

\section{DISCUSSION}

This study investigated if depth-of-cure evaluations could be affected by the substrate that surrounds the composite tested. Depth-of-cure of composites determined with Vickers hardness was compared between samples that were light-activated in a slot-shaped preparation in plaster mold or tooth. We found that the bulk-fill composites we tested achieved higher hardness values when 
Table 2: Vickers hardness numbers (mean \pm SD) of composite samples cured in plaster covered-slot or tooth covered-slot methods at different depths

\begin{tabular}{|c|c|c|c|c|c|c|c|c|}
\hline \multirow[b]{2}{*}{ Depth $(\mathrm{mm})$} & \multicolumn{2}{|c|}{ Tetric EvoCeram Bulk Fill } & \multicolumn{2}{|c|}{ Venus Bulk Fill } & \multicolumn{2}{|c|}{ Filtek Bulk Fill Flowable } & \multicolumn{2}{|c|}{$\begin{array}{c}\text { Filtek Supreme Ultra } \\
\text { Universal }\end{array}$} \\
\hline & Plaster & Tooth & Plaster & Tooth & Plaster & Tooth & Plaster & Tooth \\
\hline 0 & $47.9 \pm 4.5$ & $\mathrm{n} / \mathrm{a}$ & $21.2 \pm 0.5$ & $\mathrm{n} / \mathrm{a}$ & $24.0 \pm 1.4$ & $\mathrm{n} / \mathrm{a}$ & $79.1 \pm 3.7$ & $\mathrm{n} / \mathrm{a}$ \\
\hline 0.5 & $43.0 \pm 4.6$ & $51.8 \pm 4.4$ & $19.7 \pm 1.8$ & $20.6 \pm 3.1$ & $23.7 \pm 1.0$ & $25.0 \pm 1.4$ & $72.1 \pm 6.1$ & $74.6 \pm 6.6$ \\
\hline 1.0 & $38.9 \pm 5.4$ & $47.6 \pm 3.0$ & $18.2 \pm 2.1$ & $18.9 \pm 1.9$ & $22.3 \pm 1.1$ & $23.6 \pm 1.3$ & $60.2 \pm 13.8$ & $63.2 \pm 6.8$ \\
\hline 1.5 & $34.1 \pm 3.4$ & $40.7 \pm 3.3$ & $16.7 \pm 1.6$ & $17.8 \pm 2.0$ & $20.6 \pm 0.8$ & $21.5 \pm 0.8$ & $45.2 \pm 13.2$ & $48.6 \pm 10.4$ \\
\hline 2.0 & $31.2 \pm 4.3$ & $37.1 \pm 3.6$ & $15.4 \pm 1.4$ & $16.6 \pm 1.9$ & $18.2 \pm 1.7$ & $19.6 \pm 1.6$ & $31.8 \pm 10.5$ & $36.7 \pm 13.9$ \\
\hline 2.5 & $24.9 \pm 4.2$ & $31.0 \pm 2.8$ & $13.5 \pm 1.1$ & $15.1 \pm 2.0$ & $15.5 \pm 1.3$ & $17.8 \pm 1.3$ & $17.9 \pm 10.6$ & $19.3 \pm 7.6$ \\
\hline 3.0 & $18.7 \pm 3.8$ & $26.4 \pm 4.7$ & $11.7 \pm 1.2$ & $14.3 \pm 1.8$ & $12.8 \pm 1.2$ & $15.8 \pm 1.8$ & $5.7 \pm 2.6$ & $9.8 \pm 5.5$ \\
\hline 3.5 & $12.5 \pm 3.5$ & $21.6 \pm 4.7$ & $9.3 \pm 0.8$ & $12.9 \pm 2.3$ & $10.2 \pm 1.1$ & $13.3 \pm 1.7$ & & \\
\hline 4.0 & $6.9 \pm 2.3$ & $17.3 \pm 5.6$ & $6.9 \pm 0.9$ & $11.8 \pm 2.2$ & $7.8 \pm 1.0$ & $12.3 \pm 2.1$ & & \\
\hline 4.5 & & & $5.4 \pm 0.8$ & & $5.7 \pm 0.9$ & & & \\
\hline 5.0 & & & $4.0 \pm 0.6$ & & $4.1 \pm 0.9$ & & & \\
\hline 5.5 & & & $2.7 \pm 0.4$ & & $2.7 \pm 0.7$ & & & \\
\hline
\end{tabular}

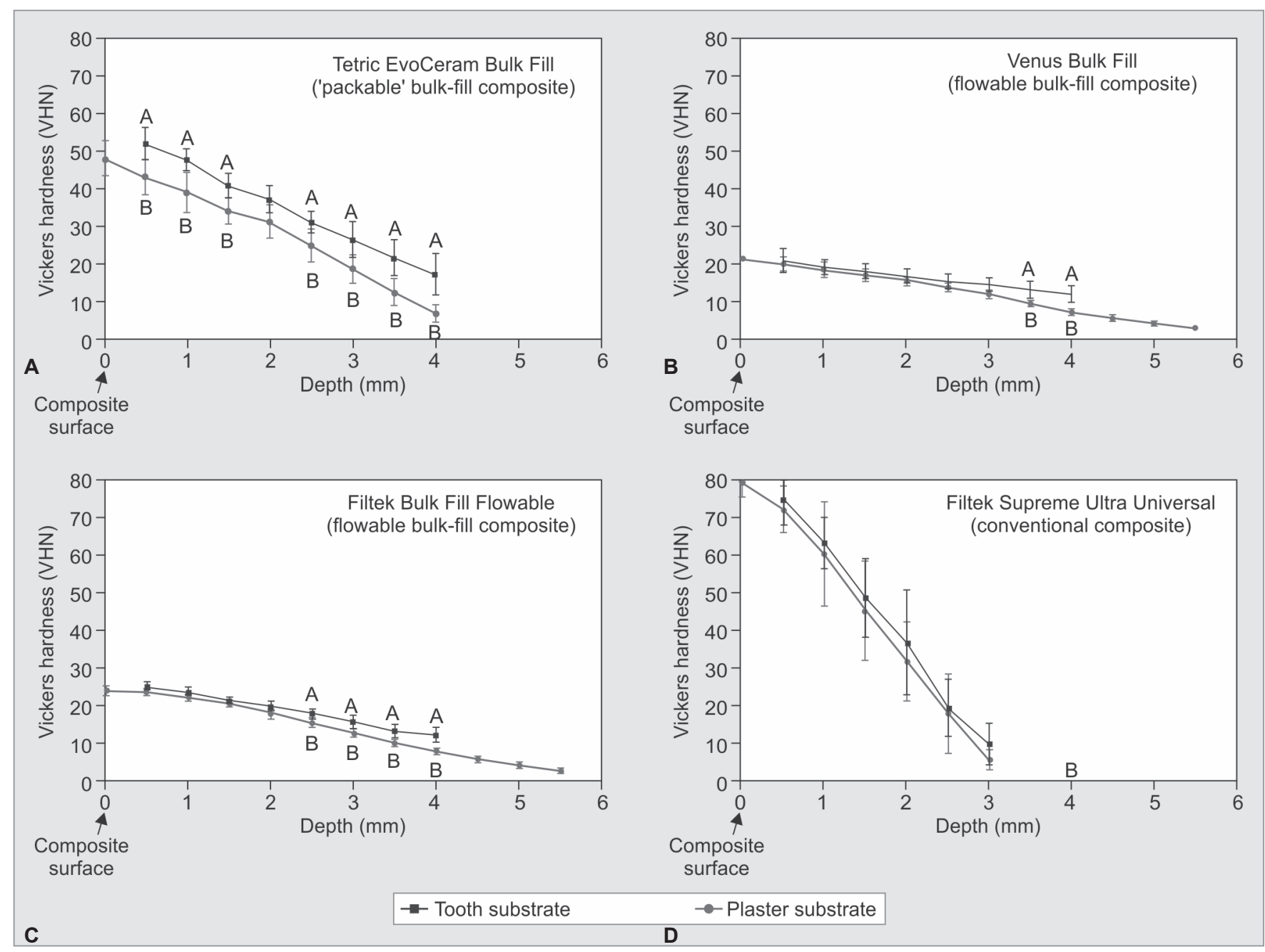

Graphs 1A to D: (A-D) Hardness profiles (mean and SD) of composites cured in plaster slots or tooth slots. Capital letters in the graphs indicate statistically significant differences between plaster slot and tooth slot at the same depth within the same composite (two-way ANOVA followed by pairwise comparisons at 0.05 significance level)

light-cured in the tooth substrate than when light-cured in the plaster, even though the light tip was about $2 \mathrm{~mm}$ further from the composite surface. Therefore, the null hypothesis that the substrate would make no difference was rejected. The optical properties of the semi-translu- cent tooth substrate apparently delivered more light at greater depth to the composite than the opaque plaster mold. No difference between substrates was found for the conventional composite, which had the steepest decline in hardness (Graph 1D), illustrating why it should be cured 


\begin{tabular}{lllll}
\hline \multicolumn{5}{c}{ Table 3: Results ( $\mathrm{p}$ values) from two-way ANOVA statistics } \\
\hline Source & Tetric EvoCeram Bulk Fill & Venus Bulk Fill & Filtek Bulk Fill Flowable & Filtek Supreme Ultra Universal \\
\hline Depths & 0.0001 & 0.0001 & 0.0001 & 0.0001 \\
Methods & 0.0001 & 0.0001 & 0.0001 & $0.1516 \mathrm{NS}$ \\
Depths*Methods & $0.8389 \mathrm{NS}$ & 0.0419 & 0.0128 & $0.9982 \mathrm{NS}$ \\
\hline
\end{tabular}

NS: Nonsignificant

incrementally to achieve an acceptable cure. The relatively shallower curing depth may explain the lack of substrate effect. Greater light delivery through the tooth substrates is most effective at greater depths (Graphs 1B and C). Moreover, in order to reach the area where the measurements were taken (middle of the sample surface, against the orange glass), light must be transmitted through the surrounding composite. Conventional composites are less translucent than bulk-fill composites, ${ }^{28}$ thus the extra light may not have been sufficient to make a significant difference in the measurement area. Note that depth-of-cure may still have been improved by the tooth substrates at the composite-tooth interface. ${ }^{25}$ Differences between the tooth and plaster substrates were more prominent in the nonflowable (packable) Tetric Evoceram Bulk Fill Flowable than in the flowable Venus Bulk Fill or Filtek Bulk Fill (Graph 1). In addition, the steeper hardness decline of Tetric Evoceram Bulk Fill compared with the other bulk-fill composites suggested that it was more difficult to cure at greater depths, which is consistent with findings in other studies. ${ }^{8,15,16}$

Depth-of-cure could also be characterized by the last point that the hardness could be measured before the composite becomes too soft for the indentation test. Venus Bulk Fill and Filtek Bulk Fill Flowable had measurable hardness up to $5.5 \mathrm{~mm}$; Tetric Bulk Fill was measurable up to $4 \mathrm{~mm}$; and Supreme was measurable up to $3 \mathrm{~mm}$. The depth of the last measurable point may appear similar to the depth-of-cure determined in ISO 4049, in which uncured composite is scraped away and the depth of remaining composite is considered cured..$^{18}$ However, hardness values at the last measurable points were $<15 \%$ of the values at the top surface. Clinically, such low hardness is not likely to be considered sufficiently cured. Therefore, it can be argued that depth-of-cure values determined by the ISO 4049 standard may not be clinically relevant. Other studies have also suggested that this ISO standard overestimates cured conditions, ${ }^{3}$ have divided the value by $2,{ }^{8}$ or found that dividing by 2 was still an overestimation. ${ }^{19}$

Another depth-of-cure method measures the top and bottom hardness of a sample. Bottom/top hardness ratio of 0.8 (or $80 \%$ of maximum hardness) has been widely used to indicate sufficient curing of composites. Flowable bulk-fill composites, in particular Venus Bulk Fill, had depth-of-cure of $4 \mathrm{~mm}$ or more using the $80 \%$ bottom/top hardness ratio. ${ }^{8,10-12,15}$ However, we found that hardness in Venus Bulk Fill composite started to drop below $80 \%$ hardness at $1.5 \mathrm{~mm}$ depth in the plaster mold and at $2.0 \mathrm{~mm}$ depth when cured in the tooth slot. In other words, depth-of-cure for the bulk-fill composites in this study did not support the $4 \mathrm{~mm}$ curing depth but suggested sufficient curing up to $2 \mathrm{~mm}$. Depth-of-cure based on the transition from glassy to rubbery state or elastic modulus has been shown to be about half of the depth-of-cure from the $80 \%$ bottom/top hardness method. ${ }^{19}$ This number appears to confirm our results. Studies that found $4 \mathrm{~mm}$ depth-of-cure used metal molds, such as stainless steel or brass. ${ }^{8,10-12}$ Metal substrates may be reflective unlike the plaster mold/orange glass used in the present study. Whereas reflective molds appear to overestimate and plaster molds may underestimate depth-of-cure, using tooth substrate in a covered-slot method should best represent the clinical conditions.

Depth-of-cure of composites has also been determined in restored teeth..$^{13,26}$ Since the composite surface has to be flat and smooth for accurate measurement of microhardness, the restored teeth had to be crosssectioned, embedded, and polished. Each of these procedures could increase composite hardness values. In the present study, the composite in the slot was cured against an orange glass plate (to block the blue curing light) to achieve a surface quality that was suitable for hardness measurement without the need of additional surface treatments and without allowing light activation from other directions than the illuminated external tooth and restoration surface. Therefore, the depth-of-cure measured with the tooth covered-slot method that we introduced in this study may most closely resemble the curing under clinical conditions. Using the tooth coveredslot technique, we showed that bulk-fill composites cured deeper than a conventional composite. Among the bulkfill composites, the two flowable bulk-fills cured deeper than the "packable" bulk-fill.

\section{CONCLUSION}

Natural tooth substrates used in the covered-slot technique slightly increased depth-of-cure of bulk-fill composites compared with an opaque plaster substrate, but no difference was found in depth-of-cure of a conventional composite. The effect of the substrate was most pronounced in a "packable" bulk-fill composite. Bulk-fill composites cured deeper than the conventional composite. 


\section{REFERENCES}

1. Yap AUJ. Effectiveness of polymerization in composite restoratives claiming bulk placement: impact of cavity depth and exposure time. Oper Dent 2000 Mar-Apr;25(2):113-120.

2. Poskus LT, Placido E, Cardoso PE. Influence of placement techniques on Vickers and Knoop hardness of class II composite resin restorations. Dent Mater 2004 Oct;20(8):726-732.

3. Moore BK, Platt JA, Borges G, Chu TM, Katsilieri I. Depth of cure of dental resin composites: ISO 4049 depth and microhardness of types of materials and shades. Oper Dent 2008 Jul-Aug;33(4):408-412.

4. Bayne SC. Correlation of clinical performance with 'in vitro tests' of restorative dental materials that use polymer-based matrices. Dent Mater 2012 Jan;28(1):52-71.

5. Ivoclar Vivadent. Tetric EvoCeram ${ }^{\circledR}$ Bulk Fill Scientific Documentation. 2014 [cited 2015 Oct 29]. Available from: http:// www.ivoclarvivadent.us/p/all/composites/restorativematerials/tetric-evoceram-bulk-fill.

6. Heraeus. Venus ${ }^{\circledR}$ Bulk Fill Scientific Compendium [cited 2015 Oct 29]. Available from: http://webmedia.kulzer-dental. com/media/hkg/downloads_new/venus_5/venus_bulk_ fill_1/Scientific_Venus_Bulk_Fill_Compendium_GB.pdf.

7. 3M ESPE. Filtek Bulk Fill Flowable Restorative product brochure [cited 2015 Oct 29]. Available from: http:// multimedia. $3 \mathrm{~m}$.com $/ \mathrm{mws} /$ mediawebserver?mwsId=SS SSSu7zK1fslxtUoY_vmx_Gev7qe1 7zHvTSevTSeSSSSSS-\&fn=Filtek_bf_brochure.pdf.

8. Flury S, Hayoz S, Peutzfeldt A, Hüsler J, Lussi A. Depth of cure of resin composites: is the ISO 4049 method suitable for bulk fill materials? Dent Mater 2012 May;28(5):521-528.

9. Ilie N, Keßler A, Durner J. Influence of various irradiation processes on the mechanical properties and polymerisation kinetics of bulk-fill resin based composites. J Dent 2013 Aug;41(8):695-702.

10. Alrahlah A, Silikas N, Watts DC. Post-cure depth of cure of bulk fill dental resin-composites. Dent Mater 2014 Feb;30(2):149-154.

11. El-Damanhoury H, Platt J. Polymerization shrinkage stress kinetics and related properties of bulk-fill resin composites. Oper Dent 2014 Jul-Aug;39(4):374-382.

12. Garcia D, Yaman P, Dennison J, Neiva G. Polymerization shrinkage and depth of cure of bulk fill flowable composite resins. Oper Dent 2014 Jul-Aug;39(4):441-448.

13. Do T, Church B, Veríssimo C, Hackmyer SP, Tantbirojn D, Simon JF, Versluis A. Cuspal flexure, depth-of-cure, and bond integrity of bulk-fill composites. Pediatr Dent 2014 Nov-Dec;36(7):468-473.

14. Alshali RZ, Salim NA, Satterthwaite JD, Silikas N. Post-irradiation hardness development, chemical softening, and thermal stability of bulk-fill and conventional resin-composites. J Dent 2015 Feb;43(2):209-218.

15. Jang JH, Park SH, Hwang IN. Polymerization shrinkage and depth of cure of bulk-fill resin composites and highly filled flowable resin. Oper Dent 2015 Mar_Apr;40(2):172-180.

16. Benetti AR, Havndrup-Pedersen C, Honoré D, Pedersen MK, Pallesen U. Bulk-fill resin composites: polymerization contraction, depth of cure, and gap formation. Oper Dent 2015 Mar-Apr;40(2):190-200.

17. Li X, Pongprueksa P, Van Meerbeek B, De Munck J. Curing profile of bulk-fill resin-based composites. J Dent 2015 Jun;43(6):664-672.

18. International Organization for Standardization. International Standard ISO 4049: dentistry - resin-based filling materials. 1988/Cor.1:1992 (E).

19. Leprince JG, Leveque P, Nysten B, Gallez B, Devaux J, Leloup G. New insight into the "depth of cure" of dimethacrylate-based dental composites. Dent Mater 2012 May;28(5):512-520.

20. Ferracane JL. Correlation between hardness and degree of conversion during the setting reaction of unfilled dental restorative resins. Dent Mater 1985 Feb;1(1):11-14.

21. Santos GB, Medeiros IS, Fellows CE, Muench A, Braga RR. Composite depth of cure obtained with QTH and LED units assessed by microhardness and micro-Raman spectroscopy. Oper Dent 2007 Jan-Feb;32(1):79-83.

22. Clifford SS, Roman-Alicea K, Tantbirojn D, Versluis A. Shrinkage and hardness of dental composites acquired with different curing light sources. Quintessence Int 2009 Mar;40(3):203-214.

23. Salako NO, Cruickshanks-Boyd DW. Curing depths of materials polymerised by ultra-violet light. Br Dent J 1979 Jun;146(12):375-379.

24. Watts DC, Amer O, Combe EC. Characteristics of visiblelight activated composite systems. Br Dent J 1984 Mar;156(6): 209-215.

25. Belvedere PC. Contemporary posterior direct composites using state-of-the-art techniques. Dent Clin North Am 2001 Jan;45(1):49-70.

26. Campodonico CE, Tantbirojn D, Olin PS, Versluis A. Cuspal deflection and depth of cure in resin-based composite restorations filled by using bulk, incremental and transtooth-illumination techniques. J Am Dent Assoc 2011 Oct;142(10):1176-1182.

27. Arikawa H, Kanie T, Fujii K, Ban S, Takahashi H. Light-attenuating effect of dentin on the polymerization of light-activated restorative resins. Dent Mater J 2004 Dec;23(4):467-473.

28. Bucuta S, Ilie N. Light transmittance and micro-mechanical properties of bulk fill vs. conventional resin based composites. Clin Oral Investig 2014 Nov;18(8):1991-2000. 